\title{
MENJAGA KELESTARIAN LINGKUNGAN MARITIM PESISIR YANG BERKELANJUTAN DI KABUPATEN PIDIE DENGAN PENDEKATAN ADAT LAOT
}

\author{
Rahcmad Munazir ${ }^{1)}$, Zulfan Yusuf ${ }^{2)}$, Mujiburrahman ${ }^{3)}$, Muhammad Nur ${ }^{4)}$ \\ ${ }^{1,2,3,4)}$ Program Studi Pendidikan Sejarah, FKIP Universitas Serambi Mekkah \\ email : munazir.rm@gmail.com, zulfanyusuf49@yahoo.com,mujiburrahmanmuji@gmail.com, \\ mnur_kemala@yahoo.com
}

\begin{abstract}
This research is a study that focus on local wisdom aspect as the force behind the sustainable development, whether development in economic, social, culture, education and other aspects. The scope of this research problem is coastal development based on the local coastal wisdom itself. Where wisdom is positioned as a potential for environmentally friendly and sustainable development. So this study looks at how the strategy of Panglima Laot as an institution of adat laot or local wisdom which is a maritime cultural heritage that developed in Aceh coast in maintaining sustainable coastal environment. This research was conducted in Pidie District of Aceh Province, where Pidie District is one of the coastal regency in Aceh. By borders, the North side of the regency is bounded by the Malacca Strait, South by West Aceh and Aceh Jaya Regencies, the East with Pidie Jaya Regency and the West is bounded by the Regency of Aceh Besar. This research uses qualitative research methods. In addition, the study also uses a multi-disciplinary approach. The approach used in this research is the approach of sociology, anthropology and history. The existence of three disciplinary approaches, can provide a comprehensive description of Panglima Laot, so that the researchers can build concepts in answering research problems. The results of this study indicates that, Panglima Laot as chief of adat (custom) has its own role in regulating fishermen as coastal custom communities. The existence of Panglima Laot is strategic enough in limiting the behavior of fishing communities, especially behavior that can damage the coastal environment. To curb such behavior, the Panglima Laot undertook by customary approach as a strategy in preventing the destruction to the coastal environment caused by the behavior of fishermen. The customary approach strategy used by panglima laot as adat leader in encouraging sustainable coastal maritime conservation in Pidie District.
\end{abstract}

Keywords : strategy, panglima laot, maritime environment, sustainable

Abstrak: Penelitian ini merupakan penelitian yang melihat aspek kearifan lokal sebagai modal dalam pembangunan yang berkelanjutan, baik pembangunan dari aspek ekonomi, sosial, budaya, pendidikan dan aspek lainnya. Fokus persoalan penelitian ini adalah pembangunan pesisir yang berlandaskan pada kearifan lokal pesisir itu sendiri. Di mana kearifan diposisikan sebagai potensi pembangunan yang ramah lingkungan dan berkelanjutan. Sehingga penelitian ini melihat bagaimana strategi panglima laot sebagai lembaga adat laot atau kearifan lokal yang merupakan warisan budaya maritim yang berkembang di pesisir Aceh dalam mewujudkan pesisir yang lestari dan berkelanjutan. Penelitain ini dilakukan di Kabupaten Pidie Provinsi Aceh, di mana Kabupaten Pidie merupakan salah satu kabupten pesisir yang ada di Aceh. Secara batas wilayah, Sebelah Utara kabupaten ini berbatas dengan Selat Malaka, Sebelah Selatan dengan Kabupaten Aceh Barat dan Aceh Jaya, sebelah Timur dengan Kabupaten Pidie Jaya dan sebelah Barat berbatas dengan Kabupaten Aceh Besar. Penelitian ini mengunakan metode penelitian kualitatif. Di samping itu, penelitian ini juga menggunakan pendekatan multi disiplin ilmu. Pedekatan yang digunakan dalam penelitian ini adalah pendekatan sosiologi, antropologi dan sejarah. Adanya pendekatan tiga disiplin ilmu tersebut, dapat memberikan gambaran yang menyeluruh terhadap panglima laot, sehingga dapat terbangun konsep oleh peneliti dalam menjawab masalah penelitian. Hasil dari penelitian ini menunjukkan bahwa, panglima laot sebagai ketua adat memiliki peran tersendiri dalam mengatur nelayan sebagai masyarakat adat pesisir. Keberadaan panglima laot cukup strategis dalam membatasi perilaku masyarakat nelayan, khususnya perilaku yang merusak lingkungan pesisir. Untuk membatasi perilaku tersebut, panglima laot 
melakukan dengan pendekatan adat sebagai strategi dalam mencegah kerusakan lingkungan pesisir yang disebabkan oleh perilaku nelayan. Strategi pendekatan adat tersebut yang digunakan panglima laot sebagai pemimpin adat dalam mendorong kelestarian lingkungan maritim pesisir yang berkelanjutan di Kabupaten Pidie.

Kata kunci : strategi, panglima laot, lingkungan maritime, lestari.

Secara geografis, sebagian besar kabupaten/kota yang berada di Aceh terletak di pinggir laut, atau berbatas langsung dengan laut. Keadaan geografis tersebut mendorong sebagian masyarakat Aceh bertempat tinggal atau bermukim di pesisir pantai dan bermata pencaharian sebagai nelayan. Kondisi ini tentunya akan membuat masyarakat saling berinteraksi, baik dengan sesamanya maupun dengan alam, sehingga melahirkan budaya dan kearifan lokal (Mujiburrahaman, 2015:1). Kearifan lokal (local wisdom) sendiri dalam kamus terdiri dari dua kata: kearifan (wisdom) dan lokal (local). Dalam Kamus Inggris Indonesia, local berarti setempat, sedangkan wisdom (kearifan) sama dengan kebijaksanaan. Secara umum maka local wisdom (kearifan setempat) dapat dipahami sebagai gagasan-gagasan setempat (local) yang bersifat bijaksana, penuh kearifan, bernilai baik, yang tertanam dan diikuti oleh anggota masyarakatnya. Dalam antropologi, kearifan lokal dikenal sebagai local genus. Menurutu Gobyah, kearifan lokal (local genius) adalah kebenaran yang telah mentradisi atau ajeg dalam suatu daerah. Dalam masyarakat pesisir Aceh dikenal adanya pemimpin adat masyarakat nelayan yang disebut dengan lembaga adat panglima laot. Ini merupakan lembaga adat yang menjalankan kearifan lokal masyarakat pesisir yang dimiliki oleh masyarakat Aceh. Soerjono Soekanto (1987: 154) menyatakan bahwa masyarakat adalah orang yang hidup bersama yang menghasilkan kebudayaan. Dengan demikian tidak ada masyarakat yang tidak memiliki kebudayaan dan sebaliknya tidak ada kebudayaan tanpa masyarakat sebagai bingkai dari potret budaya tersebut. Panglima laot sebagai warisan budaya maritim, tentu sudah mengakar dalam kehidupan masyarakat Aceh yang mengatur tatalaksana kehidupan nelayan dalam berinteraksi sebagai nelayan yang menggantungkan hidupnya pada laut.

Panglima laot sudah ada sejak zaman Kerajaan Samudra Pasai pada abad ke 14, kemudian dipertegas oleh Sultan Iskandar Muda (1607-1636). Pada saat itu posisi panglima laot adalah perpanjangan tangan sultan dalam rangka mengerjakan dua tugas utama, yaitu memungut cukai dari kapal-kapal dagang yang berlabuh di pelabuhan dan memobilisasi rakyat untuk kepentingan perang (Adli dkk 2006: 7). Menurut A.M. Djuliati Suroyo (2013: 303) Aceh pada masa Sultan Iskandar Muda pernah mengeluarkan hukum adat laut, yang khusus mengatur penangkapan ikan di laut, kaitannya dengan para nelayan, upah kerja, perahu, peralatan dan lainlain. Pejabat yang mengurus semua itu adalah panglima laot. Dalil yang disebutkan di atas merupakan bukti panglima laot sudah berjalan cukup lama dalam kehidupan nelayan Aceh. Kerifan lokal lembaga adat panglima laot ini 
merupakan warisan budaya maritim Indonesia dimana ini adalah salah satu kekayan khasanah budaya bangsa Indonesia sebagai negara maritim.

Lembaga adat laot sangat menjunjung tinggi kelestarian alam laut dan pesisir, ini adalah wujud kearifan yang merupakan ruh dari lembaga adat panglima laot. Dalam masyarakat yang masih menjunjung kearifan lokalnya, penghormatan terhadap alam adalah sesuatu yang amat penting. Dalam masyarakat tersebut ditemui sejumlah prinsip dan pola perilaku yang seharusnya. Menurut Sony Keraf istilah prinsip etika dalam lingkungan yang harus diperhatikan yakni sikap hormat pada alam (respect for nature), tanggung jawab (moral responsibility for nature), solidaritas kosmis (cosmic solidarity), kasih sayang dan kepedulian pada alam (care for nature). Manusia mempunyai tanggung jawab dan kewajiban moral terhadap alam, dengan perilaku yang berpihak pada lingkungan, hidup sederhana dan selaras dengan alam, dan keadilan (Kamruzzaman Bustamam-Ahmad dkk, 2010: IX)

Kabupaten Pidie merupakan salah kabupaten pesisir yang ada di Aceh, tentu juga memiliki lebaga adat panglima laot yang mengatur kehidupan pesisir. Jumlah panglima laot lhok yang dimiliki Kabupaten Pidie berjumlah sembilan orang, ditambah satu orang panglima laot kabupaten dimana keseluruhan Kabupaten Pidie memiliki sepuluh orang panglima laot. Keberadaan panglima laot di Kabupaten Pidie sebagai pemuka adat di wilayah laut Kabupaten Pidie menarik untuk di teliti, salah satu aspek yang menarik dilihat bagaimana strategi panglima laot dalam mewujudkan lingkungan yang lestari sebagai mana wujud ruh dari sebuah kearifan. Di samping itu, keberadaan panglima laut di Pidie juga ada mengalami pasang surut, salah satunya adalah adanya pergeseran nilai dari lembaga adat itu sendiri sebagai lembaga adat. Seperti yang terjadi di lhok Kecamatan Kembang Tanjong Kabupaten Pidie, kala bantuan datang silih berganti setelah tsunami justru ini menciptakan konflik baru yang berimbas pada pelaksanaan adat oleh panglima laot (Mujiburrahman, 2015: 152).

Mengacu pada penjelasan diatas, penelitian ini dilakukan di Kabupaten Pidie untuk melihat bagaimana strategi panglima laot Kabupaten Pidie dalam mewujudkan lingkungan maritim yang lestari

\section{METODE PENELITIAN}

Penelitian ini adalah penelitian kualitatif, dimana penelitian yang menitik beratkan pada pengamatan dan wawancara, sehingga peneliti berusaha untuk mengangkat secara ideografis berbagai fenomena dan realitas sosial (Gumilar, 2005: 64). Dalam hal ini peneliti akan turun langsung kelapangan untuk mewawancarai narasumber yang relevan terhadap penelitian dan disertai observasi yang seksama. Sedangkan data sekunder adalah data-data yang didapat dari sumber bacaan dan berbagai macam sumber lainnya yang terdiri dari surat-surat pribadi, buku harian, notulen rapat, sampai dokumen-dokumen resmi dari berbagai instansi pemerintah. Data sekunder juga dapat berupa majalah, koran, buletin publikasi dari berbagai organisasi, lampiranlampiran dari badan-badan resmi seperti kementrian-kementrian, hasil-hasil studi,tesis, hasil survey, studi histories, dan sebagainya (Nazar, 2003:45). Setelah data terkumpul, kemudian 
dilanjutkan dengan analisa data dan pembahasan data untuk mendapatkan hasil dari penelitian.

\section{HASIL DAN PEMBAHASAN}

Setiap masalah yang berkembang dalam masyarakat tentunya akan dicarikan solusi oleh pihak pemangku kepentingan, dalam hal ini oleh pimpinan masyarakat itu sendiri. Setiap komunitas masyarakat memiliki pemimpin sendiri, baik yang diformalkan maupun tidak diformalkan. Di dalam masyarakat nelayan ada panglima laot yang menjadi pemimpin adat, salah satu fungsi pimpinan adalah mengatur segala bentuk tatanan dalam segala sendi kehidupan. Termasuk masalah pemeliharaan lingkungan, pemimpin memiliki kekuasaan dalam mengatur, termasuk mengatur bagaimana orang harus bersikap yang seharunya dalam menjaga lingkungan. Panglima laot, salah satu pimpinan adat yang memiliki kewenangan adat terhadap nelayan, sehingga dalam menjaga lingkungan pesisir ada pendekatan adat yang dilakukan panglima laot dalam menjaga lingkungan sebagai warisan untuk anak cucu.

\section{a. Kearifan Pesisir}

Salah satu kearifan lokal yang ada di Aceh, adalah panglima laot. Ini merupakan kearifan pesisir yang sudah berkembang sejak zaman kerajaan (Mujiburrahman, 2015:5). Panglima laot merupakan pemimpin adat di dalam masyaralat nelayan Aceh. Berdasarkan Perda Nomor 7 Tahun 2000 tentang penyelenggaraan kehidupan adat, pasal 1 ayat (14) menyebutkan yang dimaksud dengan panglima laot adalah orang yang memimpin adat istiadat dan kebiasaan-kebiasaan yang berlaku di bidang penangkapan ikan dan penyelesain sengketa. Mengacu pada Undang74
Undang No 11 Tahun 2006, panglima laot sebagai lembaga adat yang memimpin dan mengatur hukum adat di bidang laut serta masyarakat nelayan Aceh. Menurut Mujiburrahaman, panglima laot merupakan pemimpin adat terhadap persekutuan masyarakat nelayan serta yang menjalankan adat laot, hukom adat laot dan hukom meupayang serta yang mengawasinya (Mujiburrahman, 2015:21).

Panglima laot sebagai kearifan lokal pesisir aceh sangat strategis dalam mengatur semua perilaku masyarakat nelayan, selaku orang menggantungkan hidupnya terhadap laut. Keberadaan laut tentu tidak bisa dipisahkan dengan nelayan, dimana panglima laot juga sesuatu yang inheren terhadap laut dan nelayan di Aceh. Kearifan pesisir ini merupakan keayaan budaya maritim yang dimiliki oleh bangsa Indonesia sebagai Negara maritim. Panglima laot memiliki wilayah kekuasaan adat yang meliputi. Sepanjang bineh pasie (tepi pantai). Dari arah darat dimulai dari titik terakhir ombak laut pecah atau tempat tumbuhnya tanaman tapak guda (sejenis tanaman menjalar, yang daunnya mirip tapak kaki kuda) hingga ke laut lepas dalam jangkauan masyarakat adat setempat (Syarif, 2003:36-37). Setiap panglima laot memiliki wilayah kerja di setiap kuala, di mana kuala tersebut menjadi tempat berlabuh parahu nelayan. Panglima laot ini lazim dikenal dengan nama panglima laot lhok, sedangkan panglima laot kabupaten berkerja sesuai dengan wilayah kabupaten, hingga panglima laot provinsi yang meliputi wilayah kerja provinsi pula (Muji, 2015:7). Panglima laot sebagai ketua adat, atau pemimpin adat untuk 
masyarakat nelayan, tentu panglima laot memiliki peran yang besar dalam keberlangsungan proses interaksi sosial di dalam masyarakat nelayan. secara umum ada empat peranan panglima laot dalam masyarakat nelayan. Peran tersebut adalah peran pada tatanan adat laot, hukom adat laot, hukom meupayang dan menyelesaikan sengketa.

Mengacu pada monografi perikanan Daerah Istimewa Aceh (Anonim, 1973: 102) paling tidak ada empat tugas utama panglima laot. Adapun tugas-tugasnya sebagai berikut:

1. Mengawasi dan memelihara hukum adat laut.

2. Mengatur tatacara penangkapan ikan.

3. Menyelesaikan berbagai pertikaian yang terjadi dalam hubungannya dengan penangkapan ikan di laut.

4. Menyelenggarakan upacara adat laut, menangani kecelakaan di laut, gotong royong dan masalah sosial lainnya.

Dalam buku pegangan adat tgk imum menasah menyebutkan bahwa, Panglima laot adalah orang yang memimpin adat istiadat atau kebiasaan yang berlaku di bidang penangkapan ikan di laut. Selain itu lembaga ini juga bertugas mengatur tempat/areal penangkapan ikan, penambatan perahu dan menyelesaikan sengketa bagi hasil. Kekuasaan panglima laot hanya berlaku di wilayah laut meliputi semua aspek kehidupan di laut. Tugas panglimat laot tidak hanya sekedar melakukan pengaturan tetapi juga memberikan sanksi (M. Saleh, 2007: 16).

\section{b. Strategi Panglima Laot Dalam} Mewujudkan Lingkangan Maritime Yang

\section{Lestari}

Strategi berasal dari kata Strategos dalam bahasa Yunani merupakan gabungan dari Stratos atau tentara dan ego atau pemimpin. Suatu strategi mempunyai dasar atau skema untuk mencapai sasaran yang dituju. Jadi pada dasarnya strategi merupakan alat untuk mencapai tujuan. Menurut Marrus (2002: 31) strategi didefinisikan sebagai suatu proses penentuan rencana para pemimpin puncak yang berfokus pada tujuan jangka panjang organisasi, disertai penyusunan suatu cara atau upaya bagaimana agar tujuan tersebut dapat dicapai.

Dalam mewujudkan lingkungan yang lestari, panglima laot memiliki strategi khusus yang diterapakan. Startegi ini merupakan upaya yang dilakukan oleh panglima laot lhok yang ada di kawasan pidie dalam mewujudkan kelestarian alam di wilayah maritim pidie. Hukum adat merupakan hukum yang menjunjung tinggi terhadap alam. Secara rinci, hukum adat yang ada di pesisir aceh yang merupakan nialai kearfian masyarakat nelayan dapat dibagi menjadi beberapa bagian. Adat istiadat kenelayanan atau adat laot yang dimiliki oleh masyarakat Aceh secara umum dapat dibagi menjadi tiga, yang pertama adat laot, kedua hukum adat, ketiga hukom meupayang (Mujiburrahman, 2015:74). Dalam menjalankan adat tersebut dibutuhkan hukum adat yang kemudian dapat menjatuhkan hukum adat terhadap yang melangar adat. Menurut Adli Abdullah pelaksanaan adat laot dapat disederhanakan paling tidak menjadi tiga hal, yaitu: pertama pengaturan alat tangkap dan wilayah, kedua masalah pelaksanaan sosial, ketiga masalah aturan dan pelarangan yang disertai sanksi (Adli, 2006:62). Ketiga komponen adat tersebutlah yang menjadi 
niali-nilai utama dalam mewujudkan lingkungan lestari oleh panglima laot sebgai strategi dalam pencapaian solusi.

Menurut Mujiburrahman, panglima laot memiliki peran yang besar dalam masyarakat nelayan, sekurang kurangnya ada empat peran yang dimainkan oleh panglima laot. Keempat peran tersebut, diantaranya adalah (Mujiburrahman: 2015: 114-151):

1. Peranan Panglima laot dalam Menjalankan Adat Laot

2. Peranan Panglima laot dalam Menjalankan Hukom Adat Laot.

3. Peranan Panglima laot dalam Menjalanakan Hukom Meupayang

4. Peranan Panglima laot dalam Menyelesaikan Sengketa Adat

Keempat aspek peranan tersebut merupakan peran strategis turun-temurun yang dimainkan oleh panglima laot dalam mewujudkan kelestarian lingkungan. Hukum adat diperlukan untuk membatasi perilaku, dalam hal ini perilaku nelayan yang secara langsung berhubungan dengan laut. Sebagaimana diketahui, bahwa kerusakan alam laut sangat dipengaruhi oleh perilaku manusia yang tidak memberi rasa hormat kedapa alam. Di sisi lain, hukum adat juga ikut mengisi kekosongan hukum positif. Ini dapat dilihat bahwa, hukum adat tetap berlaku dalam kehidupan masyarakat. Soerjono mengemukan ada empat alasan kenapa fenomena hukum adat terus bergulir.

1. Hukum adat pasti ada, hukum tertulis tidak akan mungkin mengatur seluruh kepentingan masyarakat dan warganya secara proposional.
2. Pada masyarakat yang sedang mengalami perubahan sosial yang relatif cepat tetapi terarah, peranan hukum adat lebih menonjol dari pada hukum tertulis.

3. Di dalam kebudayaan majemuk seperti Negara kita Indonesia, eksistensi kebudayaan-kebudayaan khusus (Sub Culture) tidak mungkin diabaikan dalam kehidupan berbangsa dan bernegara.

4. Pola-pola dalam hukum adat dapat dipergunakan untuk melembagakan hukum tertulis (Adli, 2006: 24).

Penegakan hukum adat laot, adat laot dan hukum mepayang merupakan langkah strategis adat, dan ini menjadi hal yang sangat berpengaruh dalam kehidupan masyarakat nelayan dalam mewujudkan lingkungan yang lestari. Ketiga instrumentasi adat tersebut merupakan alat yang sangat efektif untuk menjaga keseimbangan alam yang lestari.

\section{Adat laot}

Adat laot merupakan sesuatu yang sudah belangsung secara turun temurun dan terus menerus sebagai komponen adat yang tidak bisa dipisahkan dari kehidupan masyarakat nelayan. Keberadaan adat laot ini merupakan strategi yang sangat potensial untuk dapat digunakan dalam membatasi perilaku para nelayan dalam bertindak yang berisiko dalam pengrusakan lingkungan pesisir maritim. Ada empat unsur adat laot yang dijalankan oleh panglima laot yaitu, adat khanduri laot, adat sosial, adat pemeliharaan lingkungan dan adat barang hanyut (Muji, 2015:114). Unsur-unsur tersebut cukup berperan dalam mewujudkan kondisi pesisir maritime yang lestari. Menurut 
panglima laot Kabupaten Pidie, adat laot salah satu jalan yang adil untuk semua pihak dalam mengintervensi para nelayan selaku orang yang menyatu dengan laut dalam bertindak supaya menjaga kelstarian alam, dan keseimbangannya.

\section{Hukom adat laot}

Hukom adat laot merupakan pantang laot pada hari-hari yang telah ditentukan. Ada beberapa hari yang telah dipantangkan untuk melaut dalam hukom adat laut Aceh. Pertama pantang melaut bagi nelayan selama satu hari, yaitu pada hari Jumat, terhitung sejak tenggelamnya matahari pada hari Kamis sampai tenggelam matahari pada hari Jumat. Kedua, pantang melaut selama tiga hari setelah tiga hari khanduri laot, dihitung sejak keluar matahari khaduri laot hingga tenggelam matahari pada hari ketiga. Ketiga, pantang melaut pada Hari Raya Idul Fitri. Pantangan ini berlaku selama tiga hari dihitung sejak tenggelam matahari pada hari megang hingga terbenam matahari pada hari kedua Idul Fitri. Keempat, pantang melaut pada Hari Raya Idul Adha selama tiga hari dihitung sejak tenggelam matahari pada hari megang hingga tenggelam matahari pada hari ketiga Idul Adha. Kelima, pantang melaut pada hari kemerdekaan 17 Agustus 1945, terhitung sejak tenggelam matahari pada tanggal 16 Agustus sampai dengan tenggelamnya matahari tanggal 17 Agustus. Sejak Aceh dilanda musibah gempa dan tsunami pada 26 Desember 2004 yang memakan banyak korban, panglima laot juga melarang melaut pada tanggal 26 Desember, terhitung sejak tenggelamnya mata hari pada 25 Desember sampai tenggelam matahari 26 Desember. Hal itu dilakukan sebagai penghormatan kepada korban tsunami dan termasuk para nelayan yang banyak menjadi korban. Kesemua pantang laot pada harihari yang telah dirincikan di atas merupakan hukom adat laot yang dijalankan oleh panglima laot (Muji, 2015:136-137).

\section{Hukom meupayang}

Hukum meupayang adalah hukum yang mengatur tatacara atau aturan dalam menangkap ikan di laut lepas. Karena tak jarang pula dalam menangkap ikan di laut juga terjadi sengketa. Hukum meupayang ikut mengatur jarak oprasi berdasarkan jenis kapal, sampai pembagian hasil.

\section{KESIMPULAN DAN SARAN}

Panglima laot dalam mewujudkan lingkungan yang lestari menggunakan strategi pendekatan adat, yaitu dengan memaksimalkan dalam penegakan hukum adat. Adapun aspek pelaksanaan adat tersbut terletak pada adat laot, hukom adat laot dan hukom meupayang. Nilainilai kearifan yang berkembang dan sudah mengakar di pesisir tersebut merupakan strategi yang dimiliki panglima laot dalam mewujudkan lingkungan pesisir yang lestari.

\section{DAFTAR PUSTAKA}

Abdullah, M. Adli, et al., (2006) Selama kearifan adalah kekayaan: Eksitensi Panglima Laot di Aceh”. Banda Aceh: Lembaga Hukom Adat Laot Aceh dan Yayasan KEHATI. Hal 7.

Bustamam-Ahmad, Kamaruzzaman, et, al., (2010). Kearifan Lokal di Laut Aceh. Banda Aceh: Center Study of Sea Customery law and Fisheries Policy 
Syiah Kuala University and Syiah Kuala

University Press. Hal IX

Dinas Perikanan Aceh. (1973). Monografi perikanan Daerah Istimewa Aceh. Banda Aceh: Dinas Perikanan Aceh.

Gumilar, Rusliwa Somantri. (2005). Memahami Metode Kualitatif. Jurnal Makara, Sosial Humaniora, 9(2), 64.

Mujiburrahaman. (2015). Perkembangan Panglima Laôt Dan Peranannya Dalam Kehidupan Masyarakat Nelayan Di Kecamatan Kembang Tanjong Kabupaten Pidie, Provinsi Aceh (19902007). Tesis Pada Jurusan Ilmu Sejarah Pasca Sarjana Universitas Diponegoro, Semarang.

Suhaidy, M. Saleh. (2007). Buku Pegangan Teungku Imeum Meunasah. Banda Aceh: Dinas Syari'at Islam Provinsi NAD. Hal 16.

Soekanto, Soeryono. (1987). Memperkenalkan Sosiologi dalam sosiologi suatu pengantar. Jakarta: Rajawali Pers. Hal. 154

Suroyo, A.M. Djuliati, et al., (2013) Sejarah Maritim Indonesia 1: Menelusuri Jiwa Bahari Bangsa Indonesia Hingga Abad ke 17. Semarang: Jeda. Hal 303.

Syarif, Sanusi M. (2003). Riwang U Laot: Leun Pukat dan Panglima Laot dalam Kehidupan Nelayan di Aceh. Banda Aceh: Yayasan Rumpun Bambu dan CSSP. Hal 38-37. 